\title{
Individual Creativity in Designing Business Processes
}

\author{
Kathrin Figl ${ }^{1}$ and Barbara Weber ${ }^{2}$ \\ 1 Vienna University of Economics and Business (WU Vienna), \\ Augasse 2-6, 1090 Vienna, Austria, \\ kathrin.figl@wu.ac.at \\ http://nm.wu-wien.ac.at/nm/figl \\ 2 University of Innsbruck, Technikerstrasse 21a, 6020 Innsbruck, Austria
}

\begin{abstract}
Designing business processes in a creative way is an important requirement for implementing process-aware information systems. In this article we investigate how process modeling competence and individual creativity style and capacity influence creativity in a business process redesign task. We explore these relationships with a laboratory experiment with 48 business students. Our preliminary results showed that process modeling competence is positively associated with the creative quality of a business process redesign, while individual creativity style and capacity measured by well-known creativity inventories seem to be less relevant. The findings underline the importance of training in process modeling to enable employees to realize their full creative potential when redesigning process models in process improvement projects.
\end{abstract}

Keywords: creativity, business process redesign, process modeling.

\section{Introduction}

Process models define the organizational procedures intended to be supported by an information system. For this reason, up-to-date and innovative process models form the basis for adequate process-aware information systems leading to organizational success.

According to the Gartner Group [9] process improvement is one of most important priorities for top management. Redesign ideas challenging existing business processes play an ever increasing role. They can lead to radical change or to continuous improvement of processes and better business performance in the long run. In that context, visual process models can help to identify process weaknesses as well as possible improvement opportunities. Visual modeling of TO-BE processes helps to imagine how changes would affect the entire business process. Moreover, in a modeling tool it is easily possible to model and subsequently analyze a variety of innovative changes and improvement opportunities for a process.

For creating novel and valuable ideas for process redesign, creative ability of the employees working with the process models is needed. According to Mumford 
[18, p. 1] "creativity and innovation are key requirements for the growth and adaptation of organizations". Companies have to identify their creative potential to enable business innovation. Identifying individual creative potential, in turn, is relevant for assembling teams and deciding who should be part of a process redesign team. Additionally, creativity training can be of relevance for teams working on processes. Nowadays, only few firms encourage creative processes or offer creativity training beyond financial incentives [3], which may even hamper creative efforts by reducing intrinsic efforts. In this article we focus on creativity on the individual level in the task context of business process improvement.

Yet, while creativity has been recognized as important requirement for business success, surprisingly little research has been published on creativity in information systems journals. Creativity is still an under-researched area in the information systems discipline and only a limited number of creativity related research questions have already been investigated 23]. A recent literature review on creativity in the information systems field [23] illustrates which research questions have been addressed so far and demonstrates that creativity is finally receiving increasing attention in the field. To give some examples - a large stream of research has for instance dealt with the design and evaluation of creativity support systems (see e.g. [17]); others have analyzed which creativity improvement techniques are appropriate for solving problems related to information systems [4] or discussed the concept and management of creativity in business process management, for instance, in creative intensive fields [25, 24].

In our work we continue along the growing interest in creativity in the information systems field. Given the high practical relevance of creative process redesign, the aim of this study is to explore the relationship between individual creativity and business process redesign. More specifically, we address the research question how creative personality style and creative capacity influence creativity in a process redesign task.

This paper is structured as follows: First, we provide a background to business process redesign and individual factors for creativity. Next, we describe the research model underlying our empirical study. Then we explain the experimental design, before the next section presents our creativity analysis and an examination of the results. The final sections discuss our results and possible limitations of the study.

\section{Theoretical Background}

\subsection{Business Process Redesign}

Business process reengineering and continuous process improvement constitute two different ends on a continuum of business process redesign. Business process reengineering refers to "fundamental rethinking and radical redesign of business processes to achieve dramatic improvements in critical, contemporary measures of performance, such as cost, quality, service and speed" [10, p. 32]. Thereby, business process reengineering largely ignores the existing process and in the 
most extreme case follows a clean sheet approach creating the redesigned process from scratch. Continuous process improvement, in turn, typically takes existing processes as a starting point and gradually improves them in an incremental manner [5]. While both approaches differ in their focus, both aim at the redesign of existing business processes and lead to a transformation of the original process model (i.e., AS-IS process) into a redesigned version (i.e., TO-BE process) improving one or more performance measures. To achieve this transformation different redesign patterns can be used as for instance cutting non-value adding tasks, changing the order of tasks or automating tasks [22].

\subsection{Creativity}

Creativity and creative problem-solving form the basis for business innovation and process redesign [14]. Similarly to other design activities, there is no single solution and no clear path to a solution in a process redesign task. A creative solution is defined as being both original and novel as well as relevant and valuable in the specific context [1]. In a business setting novelty and uniqueness of ideas are especially desirable because such ideas can lead to competitive advantage towards competitors [28]. When researching creativity three main aspects are relevant: the creative person, the creative process and the creative product [1]. In literature, researchers have also applied a fourth factor for understanding creativity in the so-called 4-Ps model: the creative press or environment [4]. In our study we intend to include three aspects and examine how creative personality (creative person) influences the solutions to a process redesign-task (creative product) using a modeling tool (creative process), the fourth factor - creative environment is held constant due to the laboratory setting.

\subsection{Individual Influence Factors for Creativity}

Although it is possible to increase individual creativity by training to some extent, some individuals are simply more creative than others [1]. Research on individual factors for creativity has revealed that besides task motivation, domainrelated skills and creativity relevant skills and abilities influence the individual's capacity for creative action [6, 1]. According to Amabile's component theory of creative performance [1, p. 367] "each component is necessary, and not one is sufficient for creativity in and of itself". Concerning domain-related skills, formal education, knowledge about a domain and technical skills are relevant [1]. Additionally, prior research has taken personality traits and characteristics as essential influence factors for idea generation into account. One of the most influential personality models in the context of creativity is the Adaption-Innovation theory by Kirton [11]. While adaptors tend to "doing things better", innovators are likely to be "doing things differently" [11]. Adaptors work out few, but realizable solutions, they pay attention to details and work out the solution incrementally with well-known techniques 7]. In contrast, innovators propose more, but less realistic solutions and might ignore rules and existing paradigms. This 
distinction directly relates to the continuum between continuous, incremental improvement [5] and radical redesign of processes [10].

\section{Research Model and Hypotheses}

Having laid out the relevant theoretical foundation related to creativity and business process redesign, we will now draw several propositions to suggest which factors will influence the creativity of a business process redesign. Concerning person-related characteristics creative style and creative capacity are two independent dimensions [12] which are both relevant for solutions to process improvement tasks. Besides person-related characteristics, domain-relevant skills are another factor contributing to the creative process [1]. We summarize our expectations about relevant influence factors in light of the theoretical considerations in the research model shown in Figure 1

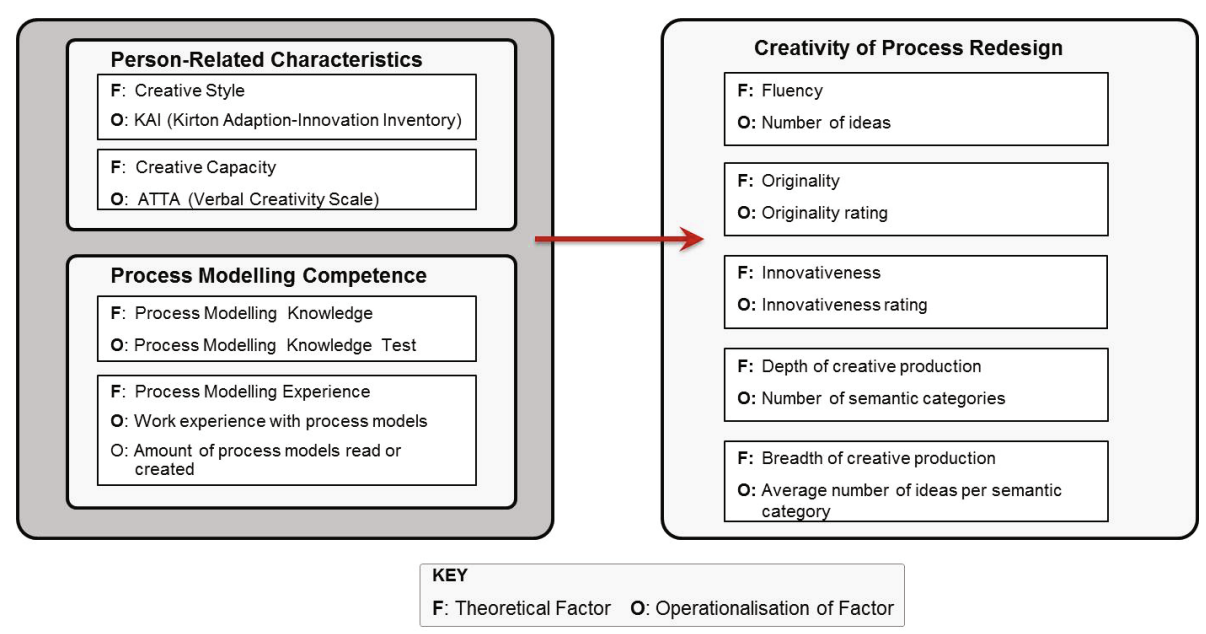

Fig. 1. Research Model

Our research model suggests that the quality of a redesigned model in a process redesign task will be a function of person-related characteristics (style and capacity) and process modeling competence (domain-relevant skills like process modeling knowledge and process modeling experience). According to [8, p. 1] we use two basic indicators of creativity: fluency is defined as "the ability to produce quantities of ideas which are relevant to the task instruction" and originality as "the ability to produce uncommon ideas or ideas that are totally new or unique". 'Fluency' is also often referred to as 'productivity' in creativity literature. In the context of business "originality is not enough. To be creative, an idea must also be appropriate - useful and actionable" [2, p. 78]. That's why we additionally use the variable innovativeness, which is defined as "the quality of 
an idea which is new and different" 27]. Fluency/productivity of ideas can be characterized in terms of amount and diversity of semantic categories to which ideas belong. The diversity of semantic categories is described as breath and the number of ideas per category is described as depth of creative production [19]. Unless noted otherwise, we expect similar effects for all five indicators for creativity of the process redesign.

Concerning the influence of creative style on creative redesign of a process we anticipate the following effects: Innovators are more likely to "break existing patterns" 16] and might produce a higher amount of innovative ideas. In contrast to innovators, adaptors perceive "boundaries less elastic and permeable" [12]. Therefore, we expect adaptors to make only small, continuous improvements to the model, leading to lower fluency, originality and innovativeness of their solutions. On the contrary, we expect innovators to radically change the process and do a complete reengineering. Thus, we conjecture that higher innovative style has a positive effect on the breath of creative production. Innovators might throw up a variety of ideas without going into detail, while adaptors might work out an idea in a very detailed way, and achieve a higher depth of creative production. In terms of our research model we expect:

- Hypothesis 1: Higher innovative style is positively associated with the fluency, originality, innovativeness and breath of creative production in a process redesign task.

- Hypothesis 2: Higher adaptive style is positively associated with the depth of creative production in a process redesign task.

Second, we turn to creative capacity. We hypothesize individual creative capacity to have a positive effect on all indicators of creative redesign. We state:

- Hypothesis 3: Creative capacity is positively associated with the creativity of the redesign.

Next, we consider process modeling competence. We speculate experience and knowledge in process modeling to contribute to the creative quality of process redesigns in terms of all indicators. Lower modeling experience might hinder creative persons from fully unfolding their capacity to provide creative ideas. Prior research has demonstrated that experience and education in the task domain are relevant for creative performance [13].

- Hypothesis 4: Process modeling knowledge is positively associated with creativity of the redesign.

- Hypothesis 5: Process modeling experience is positively associated with creativity of the redesign.

\section{Empirical Study}

To answer our research questions we conducted an empirical study using the Cheetah Experimental Platform [21]. Cheetah guides participants through a variety of questionnaire parts, offers a tutorial on process modeling and a process 
modeling tool for the redesign tasks, which logs every modeling action (e.g., adding and deleting of activities) to enable later analysis. The next paragraphs introduce main parts of the experimental design.

\subsection{Measurement of Independent Variables}

Creative Style: Innovative vs. Adaptive Problem-Solving Style (KAI (Kirton Adaption-Innovation Inventory): The Kirton Adaption-Innovation Inventory [11] measures individual problem-solving style relating to the quality of problem solutions. Respondents have to rate themselves on 32 items. It measures three different scales: sufficiency of originality, efficiency and rule governance.

Creative Capacity: Abbreviated Torrance Test of Creative Thinking (ATTA): The Torrance Tests of Creative Thinking (TTCT) measures divergent thinking and assesses the quantity and quality of creative ideas. It is a widely used (by over 2000 studies) instrument [8]. For the purpose of our study we use the verbal subscale of the abbreviated test version as a screening indicator of creative thinking abilities. The scores in the test are based on fluency (i.e., number of ideas) and originality (i.e., unusualness of ideas).

Process Modeling Competence: To measure process model competence participants are asked whether they have had any work experience with process models in practice and how many process models they have created or read. Additionally, we use a test on theoretical knowledge of process modeling developed by [15].

\subsection{Measurement of Dependent Variables: Process Redesign}

Experimental Redesign Tasks: In our experiment we ask participants to work out an improved TO-BE model for a given AS-IS process model of a coffee shop service. The AS-IS model was selected from a domain that it is understandable without any special domain knowledge. Participants got the process model (cf. Fig. 2) and the following instruction: "The coffee shop service wants to improve customer satisfaction by enhancing customer experience. How can the process be changed to implement that improvement?". The task can be characterized as a measure-invoked redesign task targeting the measure- (customer) quality [26].

Measurement of Creativity of Process-Redesigns: For analyzing the creativity of the process redesigns (the TO-BE models developed by the participants) we selected relevant criteria from literature and developed a coding schema. Multiple indicators of creativity (i.e., fluency, originality, innovativeness, depth and breath of creative production) were captured as already described in 
the research model. The creativity of the redesign ideas was assessed by two independent experts according to selected creativity indicators as described below. We deployed an iterative consensus-building process to ensure validity and reliability of our assessment. All textual content produced by participants (labels of activities and conditions) was content-coded in semantic categories. Our first analysis was based on task and condition labels; future analysis will also include further process changes as rearranged tasks.

- Fluency: Number of ideas generated

- Originality: Based on the content coding we developed a scoring schema to assign points to ideas of participants. For instance we assigned 0.5 points for a refinement or a minor change of an existing task (e.g. "waiting time $>10$ min" instead of "waiting time $>60 \mathrm{~min}$ " or "pay" instead of "pay cash"). We assigned 1 point to new labels if they were variations of existing tasks (e.g. "pay with credit card" is a variation of "pay cash"; "ask waitress for spices" is a variation of "get spices for coffee from add-on counter") or to activities which were very closely related to existing ones (e.g. "search for table" before "choose table"). In all variations either a verb or a noun in the new activity label was the same as in an existing activity label. For completely new ideas participants received 2 points each.

- Innovativeness: For ideas which were useful, purposeful and innovative for the process context and the specific task we assigned 1-2 points based on the raters' assessment. To ideas which were innovative but common (e.g. "read newspaper") we assigned 1 point, whereas to unique innovative ideas 2 points were assigned (e.g. "watching coffeemaker performing special tricks with coffee beans", "leave your coat in the cloakroom"). Ideas which cannot be influenced by the coffee shop management (e.g. "call a friend") were deemed as inappropriate in the context of the instruction and thus received no innovation points.

- Breadth of creative production: Number of semantic categories according to content categorization

- Depth of creative production: Average number of ideas per semantic category

Example of Measurement of Creativity of Process-Redesigns: In the following the creativity coding is illustrated along a redesign example of a study participant, as can be seen in Figure 2.

In the redesign solution we can see that the participant has added/changed 11 tasks or conditions resulting into 11 fluency points.

Concerning originality, "waiting time > 15 min" received only 0.5 points, as this is only a minor variation of the original label, which was commonly changed by participants (i.e., 37 out of 48 participants had changed that label). The activity "pay with EC-card" is a variation of "pay cash" and "ask for spices, if 
needed" is a variation of "get spices for coffee from add-on counter"; therefore, for both activities we assigned 1 point, respectively. All other new activities were scored with 2 points each.

The activities "receive cookie/coupon ... as a compensation", "read provided newspapers" and "watch TV (football games, music videos,...) on the big flat screen" were assigned 1 innovation point and "pay with special cafe bonus card (works with quick loading)" was assigned 2 bonus points, respectively. However, "talk to other guests" received no innovation point, since this was outside the sphere of influence of the coffee shop management.

Additionally, semantic categories were coded to determine the breath and depth of creative production. However, in contrast to other work on creativity measurement [8], we observed that in our data set the mere amount of nominations per semantic category was not an appropriate indicator for determining the creativity of an idea. For instance, activities "tip" and "eat" were only inserted once, but are not specifically creative. On the other hand, activities like "get coffee for free as a compensation for waiting time" (7 nominations) or "order online" (4 nominations) were new and innovative, but a higher amount of participants has had the same idea. A possible explanation for this may be that a higher sample size would be needed to determine uniqueness of ideas solely based on the amount of their nomination. Therefore, experts could only use the amount of nominations as an additional hint to score an idea.

\subsection{Sample}

A total of 50 business students participated in this study. Two students had to be excluded from the sample, because they had not worked on the process redesign task (they did not change anything in the models). Therefore, the final sample consisted of 48 participants. One student had not filled out the sample description items in the questionnaire, thus, we describe the remaining 47 . Of these 47 respondents, 27 were males, 20 females. $92 \%$ were currently enrolled in a Bachelor program of business administration at a large European university. 65 $\%$ have already done any process modeling (e.g., with EPCs, BPMN, Flowcharts, Petri Nets) before taking part in the study.

\section{$5 \quad$ Preliminary Results}

In this section, we report the preliminary results of testing our sets of hypotheses. Hypotheses were tested using non-parametric correlations (Spearman). Table 1 shows the main results. We describe the results for each hypothesis in turn. For hypotheses 1 and 2, we first checked the reliability of the Kirton Adaption-Innovation Inventory scales for our sample. Internal consistencies of the scales were adequate $\left(\alpha_{\text {KAI originality }}=0.63, \alpha_{\text {KAI total efficiency }}=0.81\right)$. ,$\left.\alpha_{\text {KAI rule conformity }}=0.71\right)$. Different to our expectations our data does not 
provide any support for hypothesis 1 and 2; none of the KAI subscales, nor the total score shows a significant positive correlation with any of the indicators for creativity of the redesign. Likewise, we obtained no support for hypothesis 3 , which had predicted that creative capacity is positively associated with the creativity of the redesign solutions. The process modeling knowledge test score positively correlates as expected with originality and innovativeness, but not with the other indicators of creativity. This partially supports hypothesis 4 . Hypothesis 5 predicted that experience with process models and creativity of the redesign solution are positively associated. Work experience with process models positively correlates with originality and innovativeness. The amount of process models read or created correlates positively with all creativity measures. Most strongly, the amount of process models read or created correlates with originality and innovativeness $(\rho=.342$ and $\rho=.398)$. These results lend support to hypothesis 5 . In summary, we obtained strong support for hypothesis 5 , tentative support for hypothesis 4 and no support for hypothesis 1 - hypothesis 3 .

Table 1. Correlations (Spearman's Rho, $\mathrm{n}=47-48$ ), ${ }^{+}$sign. at $\mathrm{p}<0.1{ }^{*}$ sign. at $\mathrm{p}$ $<0.05$

\begin{tabular}{|c|c|c|c|c|c|}
\hline & Fluency & Originality & Innovativeness & \begin{tabular}{|l|} 
Breadth \\
of creative \\
production
\end{tabular} & $\begin{array}{l}\text { Depth of cre- } \\
\text { ative produc- } \\
\text { tion }\end{array}$ \\
\hline $\begin{array}{l}\text { Creative Style: KAI } \\
\text { total }\end{array}$ & -.021 & .037 & .100 & -.068 & .150 \\
\hline $\begin{array}{l}\text { Creative Style: KAI } \\
\text { originality }\end{array}$ & -.133 & -.106 & -.136 & -.146 & -.059 \\
\hline $\begin{array}{l}\text { Creative Style: KAI } \\
\text { total efficiency }\end{array}$ & .014 & -.031 & -.020 & .033 & -.056 \\
\hline $\begin{array}{l}\text { Creative Style: KAI } \\
\text { rule conformity }\end{array}$ & .032 & -.009 & -.137 & .064 & -.129 \\
\hline $\begin{array}{l}\text { Creative capacity: } \\
\text { ATTA total }\end{array}$ & .051 & -.034 & -.086 & .048 & .051 \\
\hline $\begin{array}{l}\text { Creative capacity: } \\
\text { ATTA fluency }\end{array}$ & .072 & -.004 & -.098 & .084 & .046 \\
\hline $\begin{array}{l}\text { Creative capacity: } \\
\text { ATTA originality }\end{array}$ & .004 & -.075 & -.049 & -.018 & .048 \\
\hline $\begin{array}{l}\text { Process modeling } \\
\text { knowledge test }\end{array}$ & .170 & $.264^{+}$ & $.292^{*}$ & .138 & .173 \\
\hline $\begin{array}{l}\text { Work experience } \\
\text { with process models }\end{array}$ & .175 & $.251^{+}$ & $.304^{*}$ & .183 & .149 \\
\hline $\begin{array}{l}\text { Amount of process } \\
\text { models read or cre- } \\
\text { ated }\end{array}$ & $.285^{+}$ & $.342^{*}$ & $.398^{*}$ & $.257^{+}$ & $.323^{*}$ \\
\hline
\end{tabular}



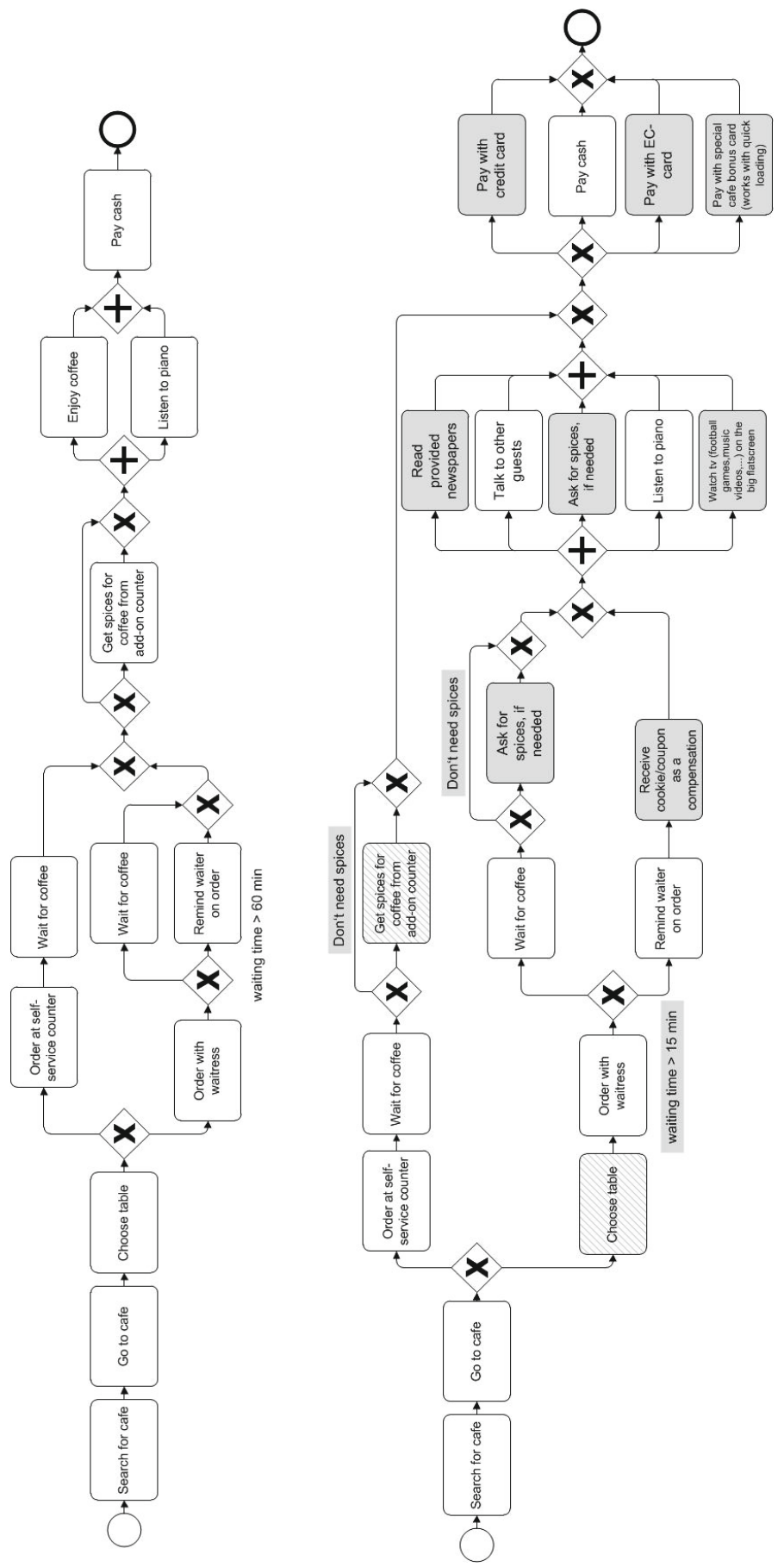

Fig. 2. Original Coffee Shop Model and Exemplary Redesign (Grey: new or changed tasks and conditions, Shaded: change of task order) 


\section{Discussion}

This study provides preliminary empirical results on the associations between individual creative style and capacity and process modeling competence and creativity in a process improvement task. According to the results obtained, process modeling experience and knowledge seems to be a necessary precondition to enable people to redesign process models in a creative way. The quantitative measure 'amount of process models read or created', which was the most exact measurement of prior experience, was the best predictor for creativity of the redesigns.

Interestingly, we obtained strongest correlations with originality and innovativeness. These two indicators of creativity were not only simple automated measures quantifying creativity, but human expert rating was involved to capture the quality of the creative ideas. While it is easy to perform an arbitrary change to a process model, higher creative effort is necessary to really improve a process and a human rating seems to be necessary to determine if an idea is creative and useful for a particular context. Our data suggests that having some experience in process modeling is an important prerequisite to be able to produce a qualitatively good redesign of a process.

The results on creative style and capacity were counter intuitive, indicating that these individual characteristics did not have any correlation with the creativity of the process redesigns. A possible interpretation is that being familiar with the task setting - process modeling - is a pre-requisite to be able to bring in own ideas. As study participants were business students without extensive process modeling background, the newness of the task might have hindered students with low process modeling experience to materialize their creative abilities, so that presumably only participants with higher prior experience could produce original and innovative ideas. Future research is needed to examine how these associations change for process model experts in practice.

Next, we want to discuss several limitations of the study. First, the usual caveats associated with laboratory experiments limit the generalizability of the results.

Second, the large number of obvious and 'non-creative' additions and changes in the process models might indicate that some participants did not make a big effort to make their solutions creative in the redesign task. Maybe the instruction restricted creativity to some extend as only purposeful solutions were sought. Prior research can account for that explanation since explicit instruction to be creative improves the creative output of individuals [20]. However, we still think the instruction was good in the way we posited it since we were interested in the task setting of redesigning a business process in a realistic way.

Third, we want to discuss the fact that we had to exclude two participants from the data set as they did not change the business process at all. We can only speculate why this was the case. Either they did not understand what to do, because the instruction was open-ended and the large choice of possible changes was overwhelming for them or they were not motivated to participate in the study or they felt intimidated from using the modeling tool. 


\section{Conclusion and Future Work}

We believe that our work serves as a valuable initial contribution for determining individual influence factors for creativity in process redesign tasks. In summary, our results indicate that process modeling competence is more relevant than individual creativity measured by existing creativity inventories. In future work we intend to validate our findings with further creative redesign tasks. Additionally, we would like to extend our analyses to include process change metrics as the amount of control flow changes, deletion and addition of routing symbols and edges of processes.

\section{References}

1. Amabile, T.M.: The social psychology of creativity: A componential conceptualization. Journal of Personality and Social Psychology 45(2), 357-376 (1983)

2. Amabile, T.M.: How to kill creativity. Harvard Business Review 76(5), 76-87 (1998)

3. Burroughs, J.E., Dahl, D., Moreau, C.P., Chattopadhyay, A., Gorn, G.J.: Facilitating and rewarding creativity during new product development. Journal of Marketing 75(4), 53-67 (2011)

4. Daniel Couger, J., Higgins, L.F., McIntyre, S.C.: (un)structured creativity in information systems organizations. MIS Quarterly 17, 375-397 (1993)

5. Davenport, T.H.: Process innovation: reengineering work through information technology. Harvard Business School Press, Boston (1993)

6. Ford, M.C.: A theory of individual creative action in multiple social domains. The Academy of Management Review 21(4), 1112-1142 (1996)

7. Foxall, G.R., Hackett, P.M.W.: The factor structure and construct validity of the kirton adaption-innovation inventory. Personality and Individual Differences 13(9), 967-975 (1992)

8. Goff, K., Paul Torrance, E.: Abbreviated Torrance Test for Adults (ATTA). Manual. Scholastic Testing Service, Bensenville, Illinois (2002)

9. Gartner Group. Leading in times of transition: The 2010 cio agenda. Technical report, Gartner, Inc. (2010)

10. Hammer, M., Champy, J.A.: Reengineering the Corporation: A Manifesto for Business Revolution. Harper Business Books (1993)

11. Kirton, M.J.: Adaptors and innovators: A description and measure. Journal of Applied Psychology 61(5), 622-629 (1976)

12. Kirton, M.J.: Have adaptors and innovators equal levels of creativity? Psychological Reports 42, 695-698 (1978)

13. Martinsen, O.: Insight problems revisited: The influence of cognitive styles and experience on creative problem solving. Creativity Research Journal 6(4), 435-447 (1993)

14. McAdam, R., McClelland, J.: Individual and team-based idea generation within innovation management: organisational and research agendas. European Journal of Innovation Management 5, 86-97 (2002)

15. Mendling, J., Strembeck, M.: Influence factors of understanding business process models. In: Proc. BIS 2008, pp. 142-153. Springer (2008)

16. Mudd, S.: Kirton adaption-innovation theory: organizational implications. Technovation 15(3), 165-175 (1995) 
17. Müller-Wienbergen, F., Müller, O., Seidel, S., Becker, J.: Leaving the beaten tracks in creative work - a design theory for systems that support convergent and divergent thinking. Journal of the Association for Information Systems 12(11) (2011)

18. Mumford, M.D., Simonton, D.K.: Creativity in the workplace: People, problems, and structures. The Journal of Creative Behavior 31(1), 1-6 (1997)

19. Nijstad, B.A., Stroebe, W., Lodewijkx, H.F.M.: Cognitive stimulation and interference in groups: Exposure effects in an idea generation task. Journal of Experimental Social Psychology 38(6), 535-544 (2002)

20. O'Hara, L.A., Sternberg, R.J.: It doesn't hurt to ask: Effects of instructions to be creative, practical, or analytical on essay-writing performance and their interaction with students' thinking styles. Creativity Research Journal 13(2), 197-210 (2001)

21. Pinggera, J., Zugal, S., Weber, B.: Investigating the process of process modeling with cheetah experimental platform. In: Proc. ER-POIS 2010, pp. 13-18 (2010)

22. Reijers, H.A., Liman Mansar, S.: Best practices in business process redesign: an overview and qualitative evaluation of successful redesign heuristics. Omega 33(4), 283-306 (2005)

23. Seidel, S., Müller-Wienbergen, F., Becker, J.: The concept of creativity in the information systems discipline: Past, present, and prospects. Communications of the Association for Information Systems 27(1), 217-242 (2010)

24. Seidel, S., Müller-Wienbergen, F., Rosemann, M.: Pockets of creativity in business processes. Communications of the Association for Information Systems 27 (2010)

25. Seidel, S., Rosemann, M.: Creativity management - the new challenge for bpm. BPTrends (2008)

26. Shtub, A., Karni, R.: Business process improvement. In: ERP, pp. 217-254. Springer, US (2010)

27. Web Finance, Inc. Innovative (2012)

28. Woodman, R.W., Sawyer, J.E., Griffin, R.W.: Toward a theory of organizational creativity. Academy of Management Review 18(2), 293-321 (1993) 